\title{
Editorial: Cellular and Molecular Mechanisms of Mycobacterium tuberculosis Virulence
}

\author{
Jianjun Sun ${ }^{1 *}$, Patricia A. Champion ${ }^{2 *}$ and Fabiana Bigi ${ }^{3 *}$ \\ ${ }^{1}$ Department of Biological Sciences, Border Biomedical Research Center, University of Texas at El Paso, El Paso, TX, \\ United States, ${ }^{2}$ Department of Biological Sciences, University of Notre Dame, Notre Dame, IN, United States, ${ }^{3}$ Institute of \\ Biotechnology, National Institute of Agricultural Technology, Buenos Aires, Argentina
}

Keywords: Mycobacterium tuberculosis, drug resistance, virulence, pathogenesis, host-pathogen interaction

Editorial on the Research Topic

Cellular and Molecular Mechanisms of Mycobacterium tuberculosis Virulence

\section{INTRODUCTION}

Mycobacterium tuberculosis $(M t b)$ is the bacterial pathogen that causes the majority of human tuberculosis (TB), the leading infectious disease in the world (Glaziou et al., 2018). Mtb invades the human host by aerosol and establishes infection in the lung by using virulence factors to combat host immunity. Over the past several decades, significant progress has been made in our understanding of $M t b$ pathogenesis. However, the mechanisms of $M t b$ virulence remain largely unknown. Moreover, the emergence of multidrug-resistant $M t b$ strains and co-infection of $M t b$ with HIV have posed new challenges in TB control. There is an urgent need to enhance our understanding of $M t b$ pathogenesis and to develop effective countermeasures against TB. This Frontiers Research Topic reports recent new findings that cover diverse aspects of cellular and molecular mechanisms of $M t b$ virulence.

\section{A New Role of the Well-Known Virulence Factor ESAT-6 in Regulating Macrophage Differentiation}

ESAT-6 (6-kDa early secreted antigenic target), a well-documented $M t b$ virulence factor, is essential for $M t b$ pathogenesis, including phagosomal rupture, mycobacterial cytosolic translocation and cell-to-cell spreading (Hsu et al., 2003; Stanley et al., 2003; Abdallah et al., 2007; van der Wel et al., 2007; Houben et al., 2012; Manzanillo et al., 2012; Simeone et al., 2012, 2015; Zhang et al., 2016). ESAT-6 appears to function as an important modulator of host inflammatory responses by manipulating several intracellular signaling pathways in macrophages, $\mathrm{T}$ cells, and epithelial cells (Tsao et al., 1999; Giacomini et al., 2001; Junqueira-Kipnis et al., 2006; Pathak et al., 2007; Koo et al., 2008; Kurenuma et al., 2009; Mishra et al., 2010; Samten et al., 2011; Wong and Jacobs, 2011; Wu et al., 2019). Here, Refai et al. report a new role of ESAT-6 in macrophage differentiation and polarization. They found that during early infection, ESAT-6 induced differentiation of M0 and M2 macrophages toward the pro-inflammatory M1 phenotype to promote granuloma formation. Subsequently, ESAT- 6 drove the phenotype switch from M1 to anti-inflammatory M2 macrophages to maintain the infection during the later persistent phases. 


\section{New Mycobacterial Factors Important for Virulence \\ RD4}

A number of regions of difference (RD) among mycobacterial species have been identified by comparative genomic studies (Mahairas et al., 1996; Behr et al., 1999; Gordon et al., 1999; Brodin et al., 2002; Lewis et al., 2003). RD1, which is present in the Mtb complex and in a related species Mycobacterium marinum, but absent from the Mycobacterium bovis Bacille Calmette-Guérin (BCG) genome, encodes an ESX-1 type VII secretion system that has been extensively investigated as a major virulence factor (Simeone et al., 2009; Tiwari et al., 2019). However, other regions of difference between mycobacterial pathogens and attenuated BCG strain have been characterized to a lesser extent. Ru et al. investigated the potential role of RD4 in virulence. $\mathrm{RD} 4$ is larger in M. marinum than in $M t b$, but absent in M. bovis, including BCG, suggesting a gradual decay of RD4 in mycobacterial genomes in the order of $M$. marinum, $M t b$, and M. bovis. The knock-in strains of BCG and M. marinum containing the entire or partial RD4 regions exhibited alterations of wild-type virulence in both mouse and zebrafish models of infection. Thus, RD4 appears to be a new locus contributing to the mycobacterial virulence.

\section{CitE}

Bacterial citrate lyase, which is important for both metabolism and virulence, is composed of three subunits, $\operatorname{CitD}(\gamma), \operatorname{CitF}(\alpha)$, and CitE ( $\beta$ ) (Griffiths et al., 2012; Torres et al., 2012). The Mtb genome encodes 2 paralogous CitE subunits (CitE1 and CitE2), but their role in $M t b$ virulence has not been explored. Arora et al. biochemically and functionally characterized the CitE enzymatic subunits. The purified CitE1 and CitE2 proteins degraded acetyl$\mathrm{CoA}$ and propionyl-CoA in vitro and the genes encoding both enzymes were up-regulated when $M t b$ was exposed to oxidative stress. Moreover, deletion of the citE genes from the $M t b$ genome reduced the resistance to oxidative stress, intracellular replication in macrophages, and growth in a guinea pig infection model. This study suggests that CitE may be a potential target for TB drug development.

\section{A Novel Phylogenetic Clade Associated Hypervirulent Strain}

Rajwani et al. analyzed the phylogenetic relatedness of a hypervirulent $M t b$ strain (H112) with a global collection of $M t b$ genomes and identified a novel phylogenetic clade that share single-nucleotide polymorphisms (SNPs) in key virulenceassociated loci, including the mcel locus and the phoP gene. This clade includes four hypervirulent strains isolated from geographically diverse regions. The common SNPs and structural variations within the clade may be considered as potential genetic determinants of hypervirulence for future studies.

\section{The Host Factors Affected by M. bovis Infection}

While $M t b$ is the most common cause of human TB, $M$. bovis can cause $\mathrm{TB}$ in both humans and cattle, making it a zoonotic threat to both food safety and public health (Cosivi et al., 1998; Renwick et al., 2007; Michel et al., 2010). Moreover, the knowledge obtained in the studies of $M$. bovis infection is valuable for understanding of $M t b$ infection due to their close relationship. In the comparative proteomic study done by Li et al., they identified proteins that were differentially regulated in human macrophages following infection with $M$. bovis, including proteins in several pathways that are similar to $M t b$ infections, such as the phagosome maturation pathway and the TNF signaling pathway. In addition, in a number of proteins and enzymes that are mainly involved in metabolic pathways, endocytosis and endosome trafficking events were found to be uniquely affected by $M$. bovis infection.

\section{New Insights Into the Drug-Resistant Mechanisms}

Drug resistance is mainly caused by mutations in the $M t b$ genome, particularly by single-nucleotide polymorphisms in genes whose protein products are directly targeted by antiTB drugs (Coculescu, 2009; Stucki and Gagneux, 2013). Hameed et al. provided a comprehensive review on the major molecular targets that are related to drug resistance mechanisms of $M t b$.

The mutations in the thyA (encoding thymidylate synthase A) and folC (encoding FolC-dihydrofolate synthase) genes have been associated with resistance to para-aminosalicylic acid (PAS; Rengarajan et al., 2004; Zhao et al., 2014; Meumann et al., 2015), a second-line anti-TB drug. Methionine is structurally related to anti-folate drugs and is shown to antagonize PAS. However, the mechanism for methioninebased antagonism remains undefined. Using both targeted and untargeted approaches, Howe et al. found that MetM, a putative amino acid transporter, plays a crucial role in the synthesis of folate precursors, which antagonizes PAS activity.

Drug induced reversion of antibiotic resistance has drawn recent attention as a prospective approach to combat drug resistance (Baym et al., 2016). FS-1, a new anti-TB drug, induces antibiotic resistance reversion in $M t b$. In the report done by Ilin et al., FS-1 was used in combination with standard anti-TB antibiotics on guinea pigs infected with an XDR-Mtb strain. The genetic changes in $M t b$ genomes following infection were analyzed and FS-1 was found to cause a counter-selection of drug-resistant variants that sped up the recovery of the infected animals from XDR-TB. While the drug resistance mutations remained intact in more sensitive isolates, reversion of drug resistance was associated with a general increase in genetic heterogeneity of the $M t b$ population.

\section{CONCLUSIONS}

The articles in this Research Topic present new findings regarding the cellular and molecular mechanisms of $M t b$ virulence, including characterization of new roles for known 
virulence factors, identification of new virulence factors, and the elucidation of drug-resistance mechanisms and reversion. This Research Topic, together with many recent publications, enhances our understanding of the mechanism of $M t b$ virulence and pathogenesis.

\section{AUTHOR CONTRIBUTIONS}

JS, PC, and FB have made a substantial, direct and intellectual contribution to the work, and approved it for publication.

\section{REFERENCES}

Abdallah, A. M., Gey van Pittius, N. C., Champion, P. A. D., Cox, J., Luirink, J., Vandenbroucke-Grauls, C. M. J. E., et al. (2007). Type VII secretion-Mycobacteria show the way. Nat. Rev. Micro. 5, 883-891. doi: 10.1038/nrmicro1773

Baym, M., Stone, L. K., and Kishony, R. (2016). Multidrug evolutionary strategies to reverse antibiotic resistance. Science 351:aad3292-2. doi: $10.1126 /$ science.aad3292

Behr, M. A., Wilson, M. A., Gill, W. P., Salamon, H., Schoolnik, G. K., Rane, S., et al. (1999). Comparative genomics of BCG vaccines by whole-genome DNA microarray. Science 284, 1520-1523. doi: 10.1126/science.284.5419.1520

Brodin, P., Eiglmeier, K., Marmiesse, M., Billault, A., Garnier, T., Niemann, S., et al. (2002). Bacterial artificial chromosome-based comparative genomic analysis identifies Mycobacterium microti as a natural ESAT-6 deletion mutant. Infect. Immun. 70, 5568-78. doi: 10.1128/IAI.70.10.5568-5578.2002

Coculescu, B.-I. (2009). Antimicrobial resistance induced by genetic changes. J. Med. Life 2, 114-23.

Cosivi, O., Grange, J. M., Daborn, C. J., Raviglione, M. C., Fujikura, T., Cousins, D., et al. (1998). Zoonotic tuberculosis due to Mycobacterium bovis in developing countries. Emerging Infect. Dis. 4, 59-70. doi: 10.3201/eid0401.980108

Giacomini, E., Iona, E., Ferroni, L., Miettinen, M., Fattorini, L., Orefici, G., et al. (2001). Infection of human macrophages and dendritic cells with Mycobacterium tuberculosis induces a differential cytokine gene expression that modulates $\mathrm{T}$ cell response. J. Immunol. 166, 7033-7041. doi: 10.4049/jimmunol.166.12.7033

Glaziou, P., Floyd, K., and Raviglione, M. C. (2018). Global epidemiology of tuberculosis. Semin. Respir. Crit. Care Med. 39, 271-285. doi: $10.1055 / \mathrm{s}-0038-1651492$

Gordon, S. V., Brosch, R., Billault, A., Garnier, T., Eiglmeier, K., and Cole, S. T. (1999). Identification of variable regions in the genomes of tubercle bacilli using bacterial artificial chromosome arrays. Mol. Microbiol. 32, 643-655. doi: 10.1046/j.1365-2958.1999.01383.x

Griffiths, E. J., Hu, G., Fries, B., Caza, M., Wang, J., Gsponer, J., et al. (2012). A defect in ATP-citrate lyase links acetyl-CoA production, virulence factor elaboration and virulence in Cryptococcus neoformans. Mol. Microbiol. 86, 1404-1423. doi: $10.1111 / \mathrm{mmi} .12065$

Houben, D., Demangel, C., van Ingen, J., Perez, J., Baldeón, L., Abdallah, A. M., et al. (2012). ESX-1 mediated translocation to the cytosol controls virulence of mycobacteria. Cell Microbiol. 14, 1287-1298. doi: 10.1111/j.1462-5822.2012.01799.x

Hsu, T., Hingley-Wilson, S. M., Chen, B., Chen, M., Dai, A. Z., Morin, P. M., et al. (2003). The primary mechanism of attenuation of bacillus Calmette-Guérin is a loss of secreted lytic function required for invasion of lung interstitial tissue. Proc. Natl. Acad. Sci. U.S.A. 100, 12420-12425. doi: 10.1073/pnas.1635213100

Junqueira-Kipnis, A. P., Basaraba, R. J., Gruppo, V., Palanisamy, G., Turner, O. C., Hsu, T., et al. (2006). Mycobacteria lacking the RD1 region do not induce necrosis in the lungs of mice lacking interferon-gamma. Immunology 119, 224-31. doi: 10.1111/j.1365-2567.2006.02427.x

Koo, I. C., Wang, C., Raghavan, S., Morisaki, J. H., Cox, J. S., and Brown, E. J. (2008). ESX-1-dependent cytolysis in lysosome secretion and inflammasome activation during mycobacterial infection. Cell Microbiol. 10, 1866-1878. doi: $10.1111 / j .1462-5822.2008 .01177 . x$

\section{FUNDING}

JS was supported by a grant from the National Institute of General Medical Sciences (SC1GM095475). PC was supported by grants from the National Institute of Allergy and Infectious Diseases (AI106872 and AI142127). The content is solely the responsibility of the authors and does not necessarily represent the official views of the National Institutes of Health. FB was supported by ANCyPT Grant PICT STARTUP 2014-3637 and PICT 2017-1721.

Kurenuma, T., Kawamura, I., Hara, H., Uchiyama, R., Daim, S., Dewamitta, S. R., et al. (2009). The RD1 locus in the Mycobacterium tuberculosis genome contributes to activation of caspase-1 via induction of potassium ion efflux in infected macrophages. Infect. Immun. 77, 3992-4001. doi: 10.1128/IAI.00015-09

Lewis, K. N., Liao, R., Guinn, K. M., Hickey, M. J., Smith, S., Behr, M. A., et al. (2003). Deletion of RD1 from Mycobacterium tuberculosis mimics bacille Calmette-Guérin attenuation. J Infect Dis. 187, 117-123. doi: 10.1086/345862

Mahairas, G. G., Sabo, P. J., Hickey, M. J., Singh, D. C., and Stover, C. K. (1996). Molecular analysis of genetic differences between Mycobacterium bovis BCG and virulent M. bovis. J. Bacteriol. 178, 1274-1282. doi: 10.1128/jb.178.5.1274-1282.1996

Manzanillo, P. S., Shiloh, M. U., Portnoy, D. A., and Cox, J. S. (2012). Mycobacterium tuberculosis activates the DNA-dependent cytosolic surveillance pathway within macrophages. Cell Host Microbe. 11, 469-480. doi: 10.1016/j.chom.2012.03.007

Meumann, E. M., Globan, M., Fyfe, J. A. M., Leslie, D., Porter, J. L., Seemann, T., et al. (2015). Genome sequence comparisons of serial multi-drug-resistant Mycobacterium tuberculosis isolates over 21 years of infection in a single patient. Microb. Genom. 1:e000037. doi: 10.1099/mgen.0.000037

Michel, A. L., Müller, B., and van Helden, P. D. (2010). Mycobacterium bovis at the animal-human interface: a problem, or not? Vet. Microbiol. 140, 371-381. doi: 10.1016/j.vetmic.2009.08.029

Mishra, B. B., Moura-Alves, P., Sonawane, A., Hacohen, N., Griffiths, G., Moita, L. F., et al. (2010). Mycobacterium tuberculosis protein ESAT-6 is a potent activator of the NLRP3/ASC inflammasome. Cell Microbiol. 12, 1046-1063. doi: 10.1111/j.1462-5822.2010.01450.x

Pathak, S. K., Basu, S., Basu, K. K., Banerjee, A., Pathak, S., Bhattacharyya, A., et al. (2007). Direct extracellular interaction between the early secreted antigen ESAT-6 of Mycobacterium tuberculosis and TLR2 inhibits TLR signaling in macrophages. Nat. Immunol. 8, 610-618. doi: 10.1038/ni1468

Rengarajan, J., Sassetti, C. M., Naroditskaya, V., Sloutsky, A., Bloom, B. R., and Rubin, E. J. (2004). The folate pathway is a target for resistance to the drug para-aminosalicylic acid (PAS) in mycobacteria. Mol. Microbiol. 53, 275-82. doi: 10.1111/j.1365-2958.2004.04120.x

Renwick, A. R., White, P. C. L., and Bengis, R. G. (2007). Bovine tuberculosis in southern African wildlife: a multi-species host-pathogen system. Epidemiol. Infect. 135, 529-40. doi: 10.1017/S0950268806007205

Samten, B., Wang, X., and Barnes, P. F. (2011). Immune regulatory activities of early secreted antigenic target of 6-kD protein of Mycobacterium tuberculosis and implications for tuberculosis vaccine design. Tuberculosis 91(Suppl. 1):S114-S118. doi: 10.1016/j.tube.2011.10.020

Simeone, R., Bobard, A., Lippmann, J., Bitter, W., Majlessi, L., Brosch, R., et al. (2012). Phagosomal rupture by Mycobacterium tuberculosis results in toxicity and host cell death. PLoS Pathog. 8:e1002507. doi: 10.1371/journal.ppat.1002507

Simeone, R., Bottai, D., and Brosch, R. (2009). ESX/type VII secretion systems and their role in host-pathogen interaction. Curr. Opin. Microbiol. 12, 4-10. doi: 10.1016/j.mib.2008.11.003

Simeone, R., Sayes, F., Song, O., Gröschel, M. I., Brodin, P., Brosch, R., et al. (2015). Cytosolic access of Mycobacterium tuberculosis: critical impact of phagosomal acidification control and demonstration of occurrence in vivo. PLoS Pathog. 11:e1004650. doi: 10.1371/journal.ppat.1004650 
Stanley, S. A., Raghavan, S., Hwang, W. W., and Cox, J. S. (2003). Achute infection and macrophage subversion by Mycobacterium tuberculosis require a specialized secretion system. Proc. Natl. Acad. Sci. U.S. A. 100, 13001-13006. doi: $10.1073 /$ pnas. 2235593100

Stucki, D., and Gagneux, S. (2013). Single nucleotide polymorphisms in Mycobacterium tuberculosis and the need for a curated database. Tuberculosis 93, 30-39. doi: 10.1016/j.tube.2012.11.002

Tiwari, S., Casey, R., Goulding, C. W., Hingley-Wilson, S., and Jacobs, W. R. (2019). Infect and Inject: how Mycobacterium tuberculosis exploits its major virulence-associated type VII secretion system, ESX-1. Microbiol. Spectr. 7. doi: 10.1128/microbiolspec.BAI-00242019

Torres, R., Chim, N., Sankaran, B., Pujol, C., Bliska, J. B., and Goulding, C. W. (2012). Structural insights into RipC, a putative citrate lyase $\beta$ subunit from a Yersinia pestis virulence operon. Acta Crystallogr. Sect. F Struct. Biol. Cryst. Commun. 68(Pt. 1):2-7. doi: 10.1107/S1744309111048056

Tsao, T. C., Hong, J., Huang, C., Yang, P., Liao, S. K., and Chang, K. S. (1999). Increased TNF-alpha, IL-1 beta and IL-6 levels in the bronchoalveolar lavage fluid with the upregulation of their mRNA in macrophages lavaged from patients with active pulmonary tuberculosis. Tuber. Lung Dis. 79, 279-285. doi: 10.1054/tuld.199 9.0215

van der Wel, N., Hava, D., Houben, D., Fluitsma, D., van Zon, M., Pierson, J., et al. (2007). M. tuberculosis and M. leprae translocate from the phagolysosome to the cytosol in myeloid cells. Cell 129, 1287-1298. doi: 10.1016/j.cell.2007.05.059
Wong, K.-W., and Jacobs, W. R. (2011). Critical role for NLRP3 in necrotic death triggered by Mycobacterium tuberculosis. Cell Microbiol. 13, 1371-84. doi: 10.1111/j.1462-5822.2011.01625.x

Wu, H., Bao, Y., Wang, L., Li, X., and Sun, J. (2019). Mycobacterium marinum down-regulates miR-148a in macrophages in an EsxA-dependent manner. Int. Immunopharmacol. 73:41-48. doi: 10.1016/j.intimp.2019.04.056

Zhang, Q., Wang, D., Jiang, G., Liu, W., Deng, Q., Li, X., et al. (2016). EsxA membrane-permeabilizing activity plays a key role in mycobacterial cytosolic translocation and virulence: effects of single-residue mutations at glutamine 5 . Sci. Rep. 6:32618. doi: 10.1038/srep32618

Zhao, F., Wang, X.-D., Erber, L. N., Luo, M., Guo, A.-Z., Yang, S.-S., et al. (2014). Binding pocket alterations in dihydrofolate synthase confer resistance to para-aminosalicylic acid in clinical isolates of Mycobacterium tuberculosis. Antimicrob. Agents Chemother. 58, 1479-87. doi: 10.1128/AAC.01775-13

Conflict of Interest: The authors declare that the research was conducted in the absence of any commercial or financial relationships that could be construed as a potential conflict of interest.

Copyright (C) 2019 Sun, Champion and Bigi. This is an open-access article distributed under the terms of the Creative Commons Attribution License (CC BY). The use, distribution or reproduction in other forums is permitted, provided the original author(s) and the copyright owner(s) are credited and that the original publication in this journal is cited, in accordance with accepted academic practice. No use, distribution or reproduction is permitted which does not comply with these terms. 